\title{
PROGRAM PENINGKATAN KEBUGARAN JASMANI DI LINGKUNGAN KELURAHAN TOMANG JAKARTA BARAT
}

\author{
Octavia Dwi Wahyuni ${ }^{1}$, Sari Mariyati Dewi ${ }^{2}$, Chrismerry Song ${ }^{3}$ \\ ${ }^{1}$ Bagian Anatomi, Fakultas Kedokteran Universitas Tarumanagara, Jakarta \\ Email: octaviaw@fk.untar.ac.id \\ ${ }^{2}$ Bagian Histologi, Fakultas Kedokteran Universitas Tarumanagara, Jakarta \\ Email: sarid@fk.untar.ac.id \\ ${ }^{3}$ Bagian Parasitologi, Fakultas Kedokteran Universitas Tarumanagara, Jakarta \\ Email: chrismerrys@fk.untar.ac.id
}

\begin{abstract}
ABSTRAK
Penyakit tidak menular (PTM) menjadi penyebab utama kematian secara global dan menyerang semua usia. Data WHO menunjukkan kematian yang terjadi di dunia hampir dua pertiganya disebabkan oleh PTM, sedangkan di Indonesia diperkirakan mencapai 75 persen pada tahun 2025. Kematian akibat PTM diperkirakan terus meningkat terutama di negara-negara menengah dan miskin. PTM bertanggung jawab terhadap tiga kali dari disability adjusted life years (DALYs) dan lima kali dari penyebab kematian dibandingkan penyakit menular. Salah satu penyebab peningkatan PTM karena kurangnya kesadaran akan berolahraga. Oleh karena itu, Kemenkes RI mencanangkan GERMAS (gerakan masyarakat hidup sehat) yang salah satunya adalah melakukan olahraga secara teratur dan terukur. Olahraga bermanfaat untuk menjaga kesehatan dan kebugaran tubuh, menguatkan sistem jantung dan pembuluh darah sekaligus mengatur berat badan. Olahraga sebaiknya dilakukan rutin 3-5x/minggu dengan total aktivitas 150 menit dan melibatkan banyak otot tubuh. Senam masal kesegaran jasmani merupakan olahraga yang paling sesuai dan mudah dilakukan. Tetapi permasalahan yang timbul pada hampir sebagian besar masyarakat Indonesia saat ini maupun warga Tomang adalah masih kurang menyadari akan pentingnya berolahraga. Provinsi DKI Jakarta sendiri menempati urutan pertama dalam besarnya penduduk dengan aktivitas fisik kurang. Bentuk kegiatan yang dilakukan untuk menggiatkan kesadaran berolahraga masyarakat Tomang adalah senam masal kesegaran jasmani. Kegiatan PKM diikuti oleh 87 peserta yang meliputi warga Kelurahan Tomang termasuk ibu-ibu PKK dan ketua RT/RW. Para peserta sangat aktif dan bersemangat saat melakukan senam. Olahraga perlu dilaksanakan secara rutin untuk meningkatkan kesehatan dan kualitas hidup warga, menurunkan angka kesakitan dan kematian akibat PTM serta meningkatkan kebersamaan warga Kelurahan Tomang.
\end{abstract}

Kata kunci: GERMAS; Penyakit tidak menular; Senam kesegaran jasmani.

\section{PENDAHULUAN}

Situasi global menggambarkan penyakit tidak menular (PTM) menjadi penyebab utama kematian secara global. Menurut Badan Kesehatan Dunia, WHO, kematian akibat Penyakit Tidak Menular (PTM) diperkirakan akan terus meningkat di seluruh dunia, peningkatan terbesar akan terjadi di negara-negara menengah dan miskin. Lebih dari dua pertiga $(70 \%)$ dari populasi global akan meninggal akibat penyakit tidak menular seperti kanker, penyakit jantung, stroke dan diabetes. Dalam jumlah total, pada tahun 2030 diprediksi akan ada 52 juta jiwa kematian per tahun karena penyakit tidak menular, naik 9 juta jiwa dari 38 juta jiwa pada saat ini. Di sisi lain, kematian akibat penyakit menular atau penyakit infeksi lainnya akan menurun dari 18 juta jiwa menjadi 16,5 juta jiwa pada tahun 2030. Pada negara-negara menengah dan miskin, PTM akan bertanggung jawab terhadap tiga beban DALYs (disability adjusted life years) dan hampir lima kali penyebab kematian dibandingkan penyakit menular, maternal, perinatal dan masalah nutrisi. Penyakit kardiovaskular merupakan penyebab terbesar (39\%) kematian PTM pada orang-orang berusia kurang dari 70 tahun, diikuti kanker (27\%), sedangkan penyakit pernafasan kronis, penyakit pencernaan dan PTM yang lain bersama-sama menyebabkan sekitar 30\%, serta $4 \%$ disebabkan oleh karena diabetes (WHO, 2011).

Pada saat yang sama, Indonesia mengalami perubahan derajat kesehatan maupun pola penyakit. WHO (2018) memperkirakan sampai tahun 2025 hampir 75\% kematian di Indonesia akibat PTM. 
Hasil Riset Kesehatan Dasar (Riskesdas) tahun 2007 dan Survei Kesehatan Rumah Tangga (SKRT) tahun 1995 dan 2001, tampak bahwa selama 12 tahun (1995-2007) telah terjadi transisi epidemiologi dimana kematian karena penyakit tidak menular semakin meningkat, sedangkan kematian karena penyakit menular semakin menurun. Di beberapa daerah yang tingkat kesehatannya lebih baik, penyakit menular sudah relatif berkurang dan beralih ke penyakit tidak menular, seperti penyakit jantung dan pembuluh darah, diabetes melitus, penyakit kronik dan degeneratif lainnya. Pergeseran pola penyakit ini juga sebagai dampak menurunnya angka kematian bayi dan anak, meningkatnya usia harapan hidup, dan peningkatan berbagai upaya kesehatan. Salah satu penyebab peningkatan PTM karena kurangnya kesadaran pola hidup sehat. Salah satu faktor risiko PTM adalah perilaku hidup yaitu merokok, konsumsi alkohol, kurang aktifitas fisik secara rutin/olahraga atau perilaku sedentari, kurang konsumsi serat, dan konsumsi lemak yang tinggi (Kemenkes RI, 2012 \& 2015).

Pemerintah melalui kementrian kesehatan RI mencanangkan GERMAS (gerakan masyarakat hidup sehat) untuk menjaga kesehatan guna mewujudkan Indonesia sehat. GERMAS merupakan gerakan nasional yang diprakarsai Presiden RI yang mengedepankan upaya promotif dan preventif tanpa mengesampingkan upaya kuratif maupun rehabilitatitif. GERMAS berfokus pada 3 kegiatan, salah satunya melakukan aktifitas fisik secara teratur dan rajin berolahraga secara rutin (Kemenkes RI, 2016). Olahraga merupakan bagian yang tidak terpisahkan dalam kehidupan sehari-hari masyarakat. Yudik Prasetyo (2013) mengatakan melalui olahraga dapat dilakukan national character building suatu bangsa, sehingga olahraga menjadi sarana strategis untuk membangun kepercayaan diri, identitas bangsa, dan kebanggaan nasional. Banyak hasil penelitian ditemukan bahwa anak-anak dan kaum muda yang aktif berolahraga, baik struktur anatomi dan anthropometriknya, fungsi fisiologisnya, stabilitas emosional dan kecerdasan intelektualnya, maupun kemampuannya bersosialisasi dengan lingkungannya nyata lebih unggul dari pada yang tidak aktif berolahraga (Kemenpora, 2017).

Olahraga penting dilakukan oleh siapa saja untuk menjaga kesehatan dan kebugaran tubuh. Aktivitas fisik teratur bermanfaat untuk mengatur berat badan serta menguatkan sistem jantung dan pembuluh darah (Kemenkes RI, 2013 \& 2015). Selain itu, olahraga dapat mengurangi risiko PTM. Agar hal tersebut dapat terjadi, olahraga baiknya dilakukan secara teratur dan terukur, yaitu rutin dilakukan selama 3-5 kali dalam seminggu dengan total aktivitas 150 menit dan melibatkan otot tubuh seperti bersepeda, berenang, jogging, lari, yoga, maupun senam aerobik. Pada pasien diabetes, olahraga sangat diperlukan untuk mengontrol gula darah. Olahraga juga bermanfaat untuk menurunkan tekanan darah, menurunkan risiko penyakit jantung, hingga stroke yang sering kali menjadi komplikasi penyakit diabetes. Berkaitan dengan segala manfaatnya, olahraga rutin tentunya akan menurunkan berat badan bagi diabetesi yang obesitas (Kemenpora, 2017). Padahal banyak berita olahraga di media massa yang menggambarkan bahwa senam kesegaran jasmani baik dan mudah dilakukan. Senam kesegaran jasmani merupakan senam aerobik ringan sebagai salah satu jenis olahraga rekreatif banyak digemari dan bisa dinikmati sampai ke daerah-daerah seluruh pelosok tanah air, mulai dari lapisan masyarakat bawah, lapisan masyarakat menengah maupun lapisan masyarakat atas. Masyarakat menganggap bahwa senam aerobik merupakan jenis olahraga yang santai, meriah, dan bisa diikuti oleh banyak orang. Selain di sanggar-sanggar senam, di kawasan perumahan dan kantor-kantor baik negeri maupun swasta, hari-hari tertentu diadakan senam aerobik dengan segala macam variasinya, dengan musik yang bisa dinikmati dan gerakan yang benar serta tarian gerak yang indah, bisa diikuti oleh semua orang, baik muda, tua, perempuan, maupun laki-laki (Sumosardjuno, 2001).

Permasalahan yang timbul saat ini adalah kurangnya kesadaran masyarakat Indonesia untuk berolahraga. Riskesdas tahun 2007 dan 2013 melaporkan penduduk Indonesia sekitar 26,1\% 
kurang melakukan kegiatan olahraga. Terdapat 22 provinsi dengan penduduk aktivitas fisik tergolong kurang aktif berada diatas rata-rata Indonesia dan propinsi DKI Jakarta menempati urutan pertama sebesar 44,2\% (Kemenkes RI, 2013). Hal ini terjadi karena kurangnya animo/minat dan apresiasi masyarakat terhadap olahraga. Dalam berolahraga, malas adalah hal yang cukup sering ditemui. Hal ini biasanya disebabkan oleh 2 dua hal, yaitu pertama, ketakutan akan sakit setelah melakukan olahraga. Contohnya rasa pegal yang muncul 1-2 hari sesudah latihan biasanya merupakan suatu pengalaman yang membuat jera, sehingga orang berpikir dua kali kalau diajak untuk kembali berolahraga. Kedua, kurangnya kesadaran terhadap pentingnya kesehatan dan kebugaran (Truna, 2010). Permasalahan tersebut juga terjadi di wilayah Kelurahan Tomang, dimana olahraga jarang dilakukan dan hanya beberapa warga yang melakukannya. Sebagian besar warga Kelurahan Tomang Jakarta Barat kurang minat dalam berolahraga. Oleh karena itu, Fakultas Kedokteran Universitas Tarumanagara mengadakan bakti kesehatan masyarakat berupa senam masal untuk menggiatkan kesadaran masyarakat Tomang untuk rutin berolahraga.

\section{METODE PELAKSANAAN PKM}

Sasaran kegiatan PKM ini adalah warga kelurahan Tomang berusia dewasa muda termasuk ibuibu PKK sebanyak 150 orang. Sebelum pelaksanaan kegiatan, tim melakukan rapat persiapan sebanyak 3 kali dan 1 kali survei ke lapangan tempat yang akan digunakan untuk kegiatan bakti kesehatan. Rapat pendahuluan dilakukan untuk membahas jenis senam apa yang dilakukan untuk menyesuaikan dengan peserta, mekanisme kegiatan dan perkiraan waktu dilakukan kegiatan. Rapat persiapan lanjutan dilakukan setelah koordinasi dengan lurah dan instansi terkait dan setelah survei lapangan. Koordinasi dilakukan dengan Lurah Tomang, Bpk. Bambang Edi Kusumo, SE untuk menyatakan maksud kedatangan dan kegiatan apa yang akan dilakukan serta meminta ijin pelaksanaan dan meminjam tempat kegiatan. Survei lapangan dilakukan untuk memeriksa dan memilih tempat mana yang luas dan sesuai untuk dilakukan kegiatan senam serta ketersediaan aliran listrik untuk sound system. Selain survei ke lapangan, koordinasi kegiatan juga dilakukan melalui media komunikasi eletronik.

Tim juga melakukan persiapan di kampus, salah satunya adalah kegiatan latihan senam kesegaran jasmani yang akan dilakukan.Latihan kegiatan senam ini dilakukan bersama dengan 5 mahasiswa yang nantinya akan menjadi instruktur senam pada saat kegiatan. Tim panitia juga melakukan kerja sama dengan ibu-ibu PKK dan bapak RT/RW yang termasuk dalam Kelurahan Tomang untuk mendata warga yang akan mengikuti kegiatan senam.

\section{HASIL DAN PEMBAHASAN}

Pada rapat persiapan kegiatan sebelumnya ditetapkan bentuk kegiatan yang sesuai untuk dilakukan adalah senam masal. Senam tersebut dipimpin langsung oleh beberapa instruktur senam sehingga peserta dapat secara langsung melihat dan mengikuti gerakan senam tersebut. Senam masal yang dilakukan adalah senam kesegaran jasmani 2012 yang diambil dari https://www.youtube.com/watch?v=z24ycGWVm7I. Kegiatan PKM senam ini diikuti oleh 87 peserta yang meliputi warga Kelurahan Tomang termasuk ibu-ibu PKK dan ketua RT/RW. Kegiatan diadakan pada hari Minggu, 27 Januari 2019, pukul 07.00-11.00 WIB di halaman parkir Kantor Kelurahan Tomang. Sebelum kegiatan dimulai, tim panitia melakukan pengecekan sound system dan men"steril'kan daerah senam. Peserta senam melakukan registrasi setengah jam sebelum kegiatan dimulai. Kegiatan PKM diawali dengan kata sambutan oleh ketua panitia kemudian dilanjutkan pemberian pengantar singkat mengenai maksud dan pentingnya kegiatan. Kegiatan senam dilakukan selama 30 menit dengan dipandu oleh mahasiswa selaku instruktur 
(Gambar 1 dan 2). Acara dilanjutkan dengan penutupan oleh ketua panitia dan foto bersama panitia (Gambar 3).

Para peserta sangat aktif dan bersemangat saat melakukan senam. Acara berjalan dengan baik lancar tanpa ada kendala, meskipun jumlah peserta tidak mencapai target yang diinginkan karena enam hari sebelum dilaksanakan kegiatan terjadi kebakaran di 3 RW Kelurahan Tomang. Setelah akhir acara, beberapa peserta termasuk ibu-ibu PKK diwawancara secara langsung mengenai apakah penting dilakukan kegiatan seperti ini. Semua peserta mengatakan seharusnya kegiatan seperti ini dapat dilakukan rutin untuk menjaga kesehatan serta mencegah penyakit. Beberapa peserta bahkan mengatakan kegiatan seperti ini dapat juga untuk meningkatkan kebersamaan warga bagi warga yang jarang berkumpul.

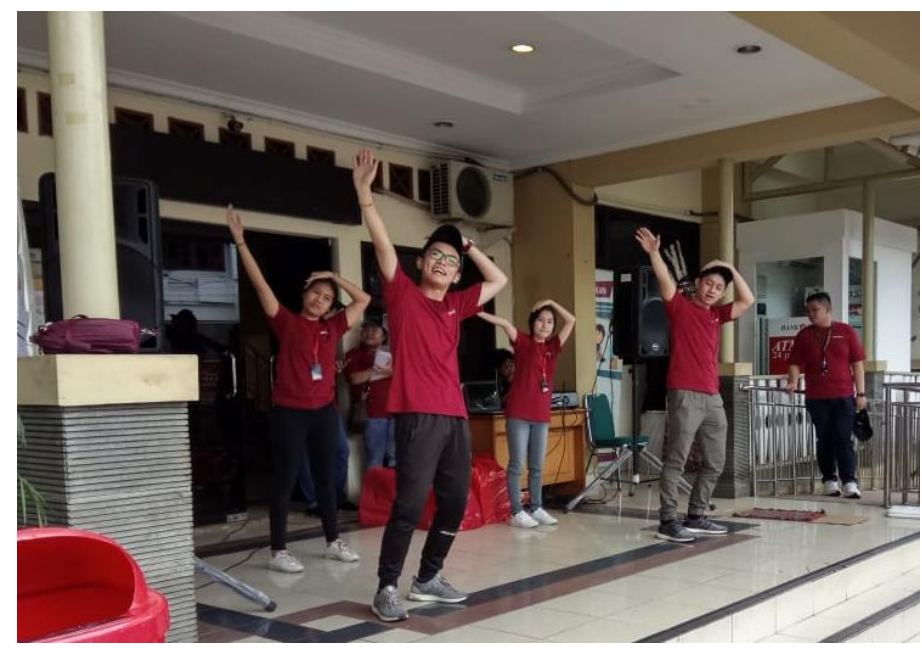

Gambar 1. Mahasiswa yang ikut berperan dalam kegiatan PKM sebagai instruktur senam

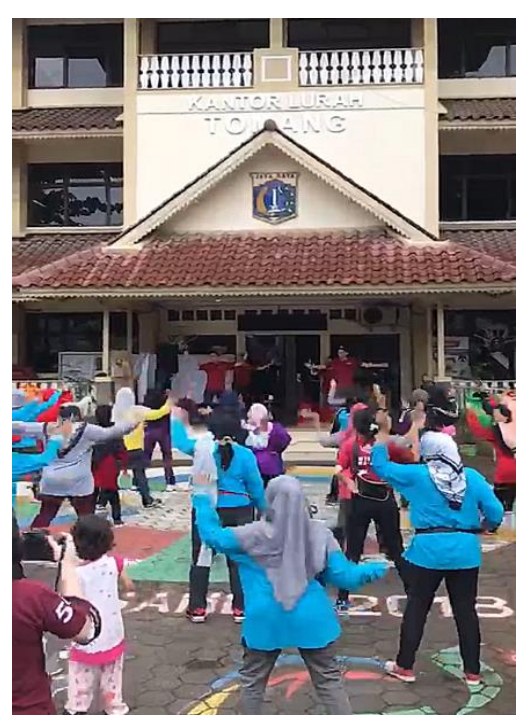

Gambar 2. Peserta melakukan kegiatan senam di halaman Kantor Kelurahan Tomang dipandu oleh instruktur 


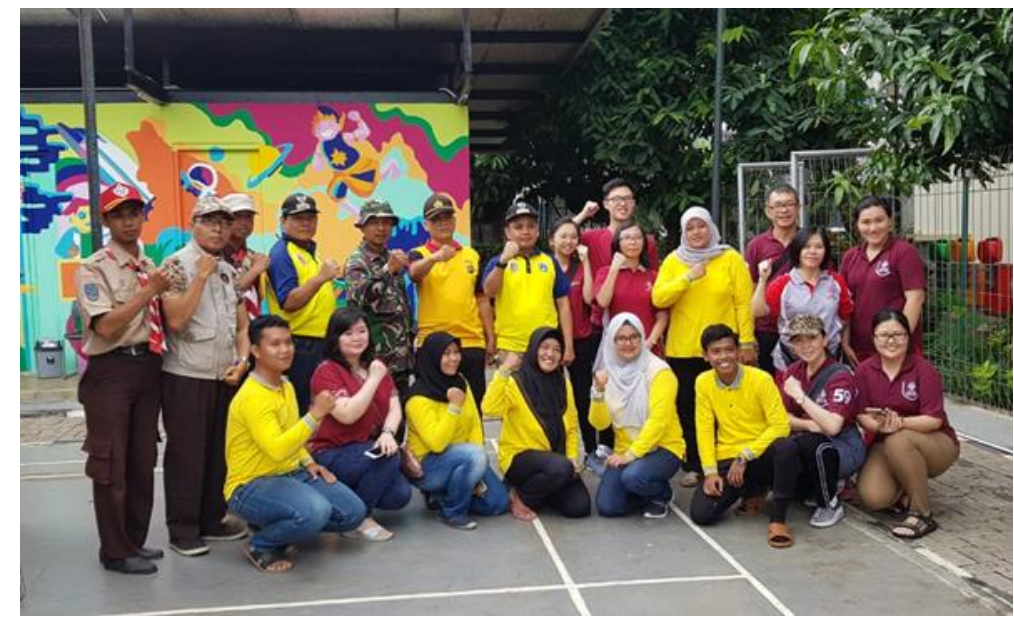

Gambar 3. Foto bersama panitia dengan instansi terkait dan ibu-ibu PKK Kelurahan Tomang seusai kegiatan.

\section{KESIMPULAN DAN SARAN}

Kegiatan PKM menjaga kebugaran jasmani seperti melakukan senam dan olahraga harus dilaksanakan secara berkala untuk dapat meningkatkan kesehatan dan kualitas hidup warga. Senam maupun olahraga yang dilakukan secara rutin juga dapat menurunkan angka kesakitan dan kematian akibat penyakit tidak menular serta dapat juga meningkatkan kebersamaan warga Kelurahan Tomang.

Berdasarkan kegiatan yang telah diselenggarakan, disarankan kegiatan PKM senam ataupun olahraga lainnya dilakukan secara rutin serta sebelum kegiatan dilakukan rapat akhir atau komunikasi ulang dengan instansi terkait untuk melihat keadaan terakhir wilayah PKM agar tidak terjadi kendala dan target peserta tercapai. Penelitian berbasis pengabdian juga dapat dikembangkan dan dilakukan berdasarkan hasil kegiatan PKM.

\section{Ucapan Terima Kasih (Acknowledgement)}

Terima kasih kepada DPPM Universitas Tarumanagara yang telah memberikan dukungan dalam bentuk dana untuk kegiatan PKM ini. Kami juga mengucapkan terima kasih kepada DPPM Fakultas Kedokteran Universitas Tarumanagara dalam memberikan arahan dan fasilitas untuk terlaksananya PKM ini. Selain, itu, kami ucapkan terima kasih kepada Lurah Tomang beserta jajarannya yang banyak membantu dalam menyediakan perizinan, sarana dan prasarana yang dibutuhkan dalam pelaksanaan kegiatan PKM. Terakhir, kami mengucapkan terima kasih kepada ibu-ibu PKK Kelurahan Tomang dan pengurus RT/RW Kelurahan Tomang yang banyak membantu dalam pelaksanaan kegiatan PKM ini.

\section{REFERENSI}

Kemenkes RI. (2012). Penyakit Tidak Menular. Buletin Jendela Data \& Informasi Kesehatan, 2(2). Diakses dari: http://www.depkes.go.id/download.php?file=download/pusdatin/buletin/buletin-ptm.pdf Kemenkes RI (2013). Riset Kesehatan Dasar 2013. Diakses dari: http://www.depkes.go.id/resources/download/general/Hasil\%20Riskesdas\%202013 
Kemenkes RI. (2015). Rencana Aksi Program Pengendalian Penyakit Dan Penyehatan Lingkungan Tahun 2015-2019. Diakses dari: http://www.depkes.go.id/resources/download/RAP\%20Unit\%20Utama\%2020152019/5.\%20Ditjen\%20P2P.pdf

Kemenkes RI. (2016). Germas wujudkan Indonesia sehat. Diakses dari: http://www.depkes.go.id/article/view/16111500002/germas-wujudkan-indonesiasehat.html

Kemenpora RI. (2017). Rencana strategis Kementerian Pemuda dan Olahraga tahun 2016- 2019. Diakses dari:

http://kemenpora.go.id/img_upload/files/Rentsra\%20Kemenpora\%2020162019\%281\%29.pdf

Prasetyo, Y. (2013). Kesadaran masyarakat berolahraga untuk peningkatan kesehatan dan pembangunan nasional. Medikora, 11(2), 219-228.

Sumosardjuno S. (2001). Latihan olahraga bagi orang dewasa. Jakarta: KONI Pusat Ilmu Keolahragaan.

Truna A. (2010). Penyebab malas olahraga. Diakses dari: http://adecheeruna.wordpress.com/kesehatan/penyebab-malas-olahraga/SKJ 2012. https://www.youtube.com/watch?v=z24ycGWVm7I.

WHO. (2011). Global status report on noncommunicable diseases 2010. Geneva: World Health Organization. Available from:

https://www.who.int/nmh/publications/ncd_report2010/en/

WHO. (2018). Noncommunicable diseases country profiles 2018. Geneva: World Health Organization. Aavailable from: https://www.who.int/nmh/publications/ncd-profiles2018/en/ 